Research Article

\title{
Development of Natural Fiber Hybrid Composites Using Sugarcane Bagasse and Bamboo Charcoal for Automotive Thermal Insulation Materials
}

\author{
Fasika Abedom $\mathbb{D}^{1}{ }^{1}$ S. Sakthivel, ${ }^{1}$ Daniel Asfaw, ${ }^{1}$ Bahiru Melese, ${ }^{1}$ Eshetu Solomon, ${ }^{1}$ \\ and S. Senthil Kumar ${ }^{2}$ \\ ${ }^{1}$ Department of Textile and Garment Technology, Faculty of Textile, Apparel and Fashion Technology, \\ Ethiopian Technical University, Addis Ababa 190310, Ethiopia \\ ${ }^{2}$ Department of Handloom and Textile Technology, Indian Institute of Handloom Technology, Salem, Tamil Nadu, India
}

Correspondence should be addressed to Fasika Abedom; fasikaabedom06@gmail.com

Received 11 April 2021; Revised 20 June 2021; Accepted 5 July 2021; Published 15 July 2021

Academic Editor: Antonio Caggiano

Copyright (c) 2021 Fasika Abedom et al. This is an open access article distributed under the Creative Commons Attribution License, which permits unrestricted use, distribution, and reproduction in any medium, provided the original work is properly cited.

\begin{abstract}
The effective utilization of fibers from natural sources is the main objective of this research work, but natural fibers alone are not meeting the required strength properties. The objective of this study focuses on the experimental study of composites developed from bagasse fiber/bamboo charcoal for technical applications by investigating its diverse mechanical and thermal insulating properties. For this investigation, five hybrid composites with bagasse fiber/bamboo charcoal proportions of 100\%/0\%, 70\%/30\%, $50 \% / 50 \%, 30 \% / 70 \%$, and $0 \% / 100 \%$ with $65 \%$ polyurethane foam in all by using compression molding technique and their mechanical properties are evaluated experimentally under the ASTM standards. The fiber alignments, internal crack, and binding properties are checked by morphological test. It is observed that the tensile strength of sugarcane bagasse/charcoal composites produces $255.80 \mathrm{MPa}$ which is approximately the same strength $(260.10 \mathrm{MPa})$ as artificial fiber composites. The bagasse fiber/ bamboo charcoal 30/70-based composites show a higher thermal insulation coefficient than the other four samples-reinforced composites. The impact and flexural strength of the 30/70 sample are higher than those of other samples. The results obtained report the possibility of exploitation of natural fiber sugarcane bagasse and bamboo charcoal for the production of reinforcements based on composites with good mechanical and thermal characteristics to utilize as automotive interior materials in component systems.
\end{abstract}

\section{Introduction}

Natural fiber offers many technical and ecological benefits for its use in reinforced composites. For the use of plastics, many natural fiber types have been investigated such as sugarcane, bamboo, flax, wood, hemp, jute, sisal, barely, wheat, and sisal, and the matrix materials used for reinforcing the fibers are classified as thermosets, thermoplastics, and elastomers [1]. For thousands of years, plant fibers are a kind of renewable source which have been renewed by nature within their variation in properties and characterization [2-4]. In tropical areas, sugarcane with a genus name
Saccharum spp. is commonly cultivated. 1.7 billion tons of sugarcane were produced worldwide in 2011. Bagasse is a residue of $30 \%$ in the amount left after crushing the cane stalk in either alcohol or sugar mills. Bagasse is extracted from different parts of the cane stalk consisting of the crushed inner pith and the outside rind [5]. It contains $45 \%$ of fiber, composed of $45 \%$ cellulose, $33 \%$ hemicelluloses, and $20 \%$ lignin [6]. The composites are compound materials that differ from alloys by the fact that the individual components retain their characteristics but are so incorporated into the composite as to take advantage only of their attributes and not of their shortcomings, in order to obtain improved 
materials [7]. The heterogeneous constituting materials consisting of two or more solid phases, in which their intimacy is detected by the aid of a microscopic scale, are explained by Suchetclan [8].

They can be also considered homogeneous materials on a microscopic scale in the sense that any portion of them will have the same physical property. The idea of using bamboobased biocomposite materials has given birth due to its usage of furniture production with an accepted long-term global impact forced researchers to get answers to various problems through research and development [9]. Research and development are important for the improvement of production and quality of manufacturing for bamboo-based biocomposite industries. After preparation and characterization in combination with other fiber sources, bamboo charcoal particles can be applied for thermophysiological comfort properties [10]. Peculiar properties of reinforced biocomposite from natural bamboo fiber increase its flexural and tensile strength, ductility, and greater cracking resistance and greater than better toughness and impact strength of the composite [11]. Bamboo productions dated back thousands of years ago and thus they are rich with traditional elements. Bamboo is easily accessible all over the globe [12]. For varieties of benefits and uses, bamboo is suitable naturally. This natural gift is often applied as a material for paper sheet production, in addition to their use in erosion control. High strength, processing easiness, fiber usage sustainability, environmental friendliness, and the fast-growing cycle of the plant are the characteristics that can be taken as merit. Rather than any other synthetic-origin reinforced composites like glass fiber, reinforced composites from bamboo fiber sources are focused these days on having enhanced eco-friendly use as they have less impact on the environment with allowing the releasing of less toxic gases [13]. By taking into consideration its positive features towards life, mercy, prosperity, and peace are the naming given to using bamboo plants sometimes by some peoples. Due to its high strength and lightweight properties [3], it takes researchers' focus for exploring and investigation in the field of biocomposite bamboo field especially and is awarded as one of the green technologies which is responsible fully for the producing eco-friendly environment. Many researchers have identified bamboo-origin solid wood agricultural biomass as a major source of cellulosic natural fiber biocomposite, provided at a minimum cost, and this will bring a new evolution into the production chain and manufacturing world $[14,15]$. For the construction industry, better elastic and strength materials are chosen and suitable, and these requirements are proven and fulfilled by bamboo for serving as a foundation structural works. However, natural fiber composites have proven to be more suitable considering most criteria except strength as findings have revealed glass fibers to be stronger. In various industries, there is a certain increment in many applications of natural fibers due to its proven findings in properties of environmental and economic friendliness of natural fibers compared to synthetic fiber [16]. Natural fibers are from plants containing lingocellulosic substances and are environmentally friendly due to their strength, availability, renewability, and biodegradability, such as cotton, jute, sisal, bagasse, hemp, coir, and hemp. For industries, naturally sourced composites are proudly fit for noncarcinogenicity and biodegradability and thus are preferred widely to conventional composites, with today's findings emphasizing their importance from natural fiber origins and stating its good reason for a preference [17]. In the structure of plant fibers, lignin and hemicelluloses matrix held cellulose fibrils together. By increasing the amount of cellulose, the mechanical properties of fibers increase. As a composite of reinforced polymer, cellulose fibers have been applied in automotive, bridge construction, and building. In comparison with other natural fibers, bamboo is eco-friendly with a high growth rate and $\mathrm{CO}_{2}$ atmosphere fixing, which makes it the most important plant fibers. It is found that more than 1000 species of bamboo and around 70 genera grow naturally in diverse climates, especially in Asia and South America abundantly [18]. The numerous advantages of bamboo such as high strength, lightweight, biodegradability, stiffness, and their leaves and roots keep together the soils and protect it via the reflection of sunlight, respectively. In the technical application for numerous applications and composites' steady growth areas [19], like building construction, and living tools very large in size, utilization of bamboo can be increasingly used as reinforced composite materials in a controlled manner based on appropriate extraction of fibers $[19,20]$. Researchers did not confirm the uses of natural composites for automotive applications from combinations of bagasse and bamboo sources. This paper focuses mainly on the development of natural fiber composites by using sugarcane bagasse with bamboo charcoal for automotive thermal insulation materials.

\section{Materials and Methods}

\subsection{Materials}

2.1.1. Sugarcane Bagasse Extraction. The bagasse fibers are collected from streets and chemically treated by submerging them in $500 \mathrm{ml}$ alkaline solution with $10 \% \mathrm{NaOH}$ at $60-70 \%$ for 3 hours [21]. Then, they were rinsed with distilled water to cleanse them from excess alkaline remnant on the surface then followed by drying up in an oven at temperature of $200^{\circ} \mathrm{C}$ for 30 seconds. The fiber extricated operation is shown in Figure 1.

2.1.2. Bamboo Charcoal Extraction. Bamboo stems are used and converted into charcoal and made into powder by a grinder locally. As can be seen in Figure 2, raw bamboo charcoal is made of bamboo culms which were cut into a certain length and then loaded into a kiln to dry, heat, and pyrolyze under the condition of lacking or little oxygen and then pyrolyzed [22].

2.2. Composite Preparation Process. Initially, a prepared resin is applied to the required five recipes. Samples are combined by hand layup and molded by the clean and dried molding box. The bagasse fiber and powdered bamboo charcoal are chosen for the composite groundwork and are prepared by a compression molding process [23]. For 


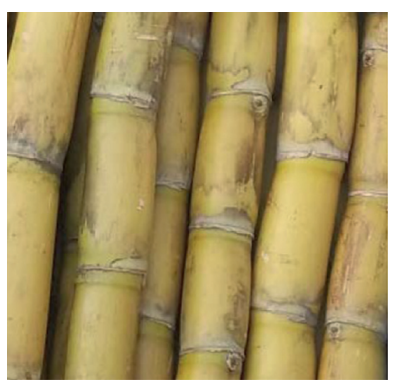

(a)

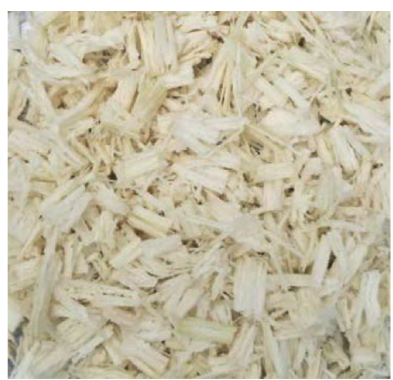

(b)

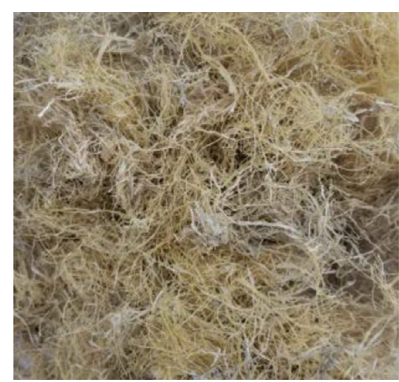

(c)

Figure 1: Bagasse fiber extraction.

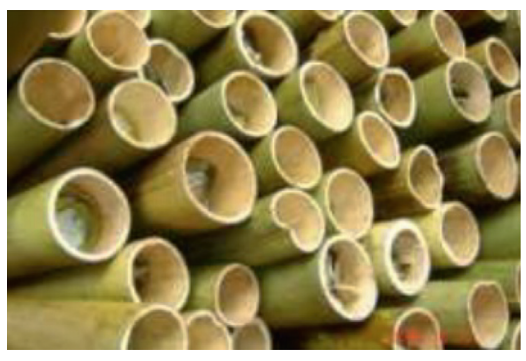

(a)

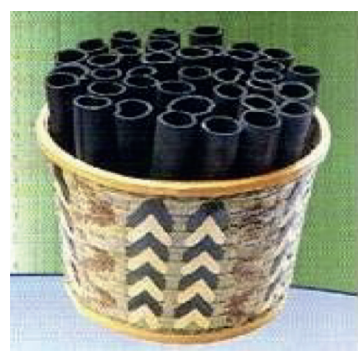

(b)

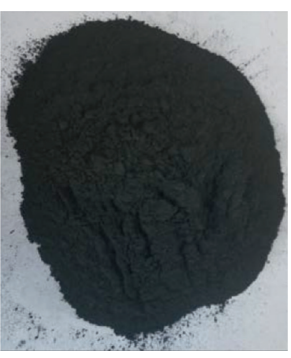

(c)

Figure 2: Charcoal powder extraction from raw bamboo stem.

composite readiness, a mold size of $250 \mathrm{~mm}$ in length $(L)$, $25 \mathrm{~mm}$ width $(W)$, and thickness $(T)$ of $6 \mathrm{~mm}$ is chosen. For testing, five example plates $(A, B$, and $C$ ) are set up according to ASTM standard size, and they will be tried for mechanical and thermal insulation properties. The different composition of the sample is given in Table 1. Both input materials are combined in different ratios of bagasse/bamboo charcoal with five samples with the aid of biodegradable resin with the following composition. Based on the following process as shown in Figure 3, the composite sample is developed.

Here for the purpose of binding biodegradable resin, polyurethane resin is used by considering its operational guidelines for better material achievement and proper applicability of the developed composite samples in test in gas per their requirements of respective ASTM standards. Matrix composites are used from these two sources, in which fiber orientation can be made very much more random and the samples are developed by compression molding techniques as this device often yields composite parts that have the optimal mechanical properties possible from the particular combination of constituent materials.

The bagasse fiber and charcoal powder are weighed based on their required appropriate recipe and the resin is added and mixed with a scattering blender with a rotating speed of $50 \mathrm{rpm}$ for 10 to 15 minutes and it is homogenously mixed and poured into the mould. After that, it fixes at room temperature for one hour at room temperature to obtaining the necessary size of composite plates [24]. The developed composite plates are shown in Figure 4.

\subsection{Mechanical Testing}

2.3.1. Tensile Test. The fabricated fiber-reinforced hybrid composites are shaped with the required dimension by saw cutter and edge preparation is done by emery sheet for tensile test. According to the ASTM D 3039, the test specimen is prepared [25]. The gauge length and cross head speed are obtained from the ASTM standards. The specimen is mounted in between the jaws and it is subjected to under tension. In the direction of fiber length, the test sample is loaded, until the fracture happened. At the same time, the reading is noted as a function of increasing in length. The measurements of tensile strength are taken parallel to fiber length. Having obtained a very precise result on tension test, the same procedure is repeated four times for the nature of natural fiber sources, matrix materials used, and arrangement of fibers affects the mechanical properties [26]. The tensile tests are directed utilizing $100 \mathrm{kN}$ universal testing machine with a speed of $50 \mathrm{~mm} / \mathrm{min}$ crosshead speed.

2.3.2. Flexural Test. A three-point flexural test is commonly conducted on a fiber composite. At present, the flexural test of the fabricated specimen is carried out under the ASTM B 790-03 standards. The test specimen is placed in between two supports and it is loaded at the center, until the failure takes on the composite specimen. The results of flexural strength are noted. The same procedure is followed four times, and finally, the mean value is reported. 
TABLe 1: Composition of prepared samples.

\begin{tabular}{lcccc}
\hline S. no. & Composition of composites & Sample code & Resin (\%) & \multicolumn{2}{c}{$\begin{array}{c}\text { Ratio (\%) } \\
\text { Bamboo charcoal (\%) }\end{array}$} \\
\hline 1 & Bagasse/bamboo & BBC-A & 65 & 100 \\
2 & Bagasse/bamboo & BBC-B & 65 & 70 \\
3 & Bagasse/bamboo & BBC-C & 65 & 50 \\
4 & Bagasse/bamboo & BBC-D & 65 & 30 \\
5 & Bagasse/bamboo & BBC-E & 65 & 70 \\
\hline
\end{tabular}

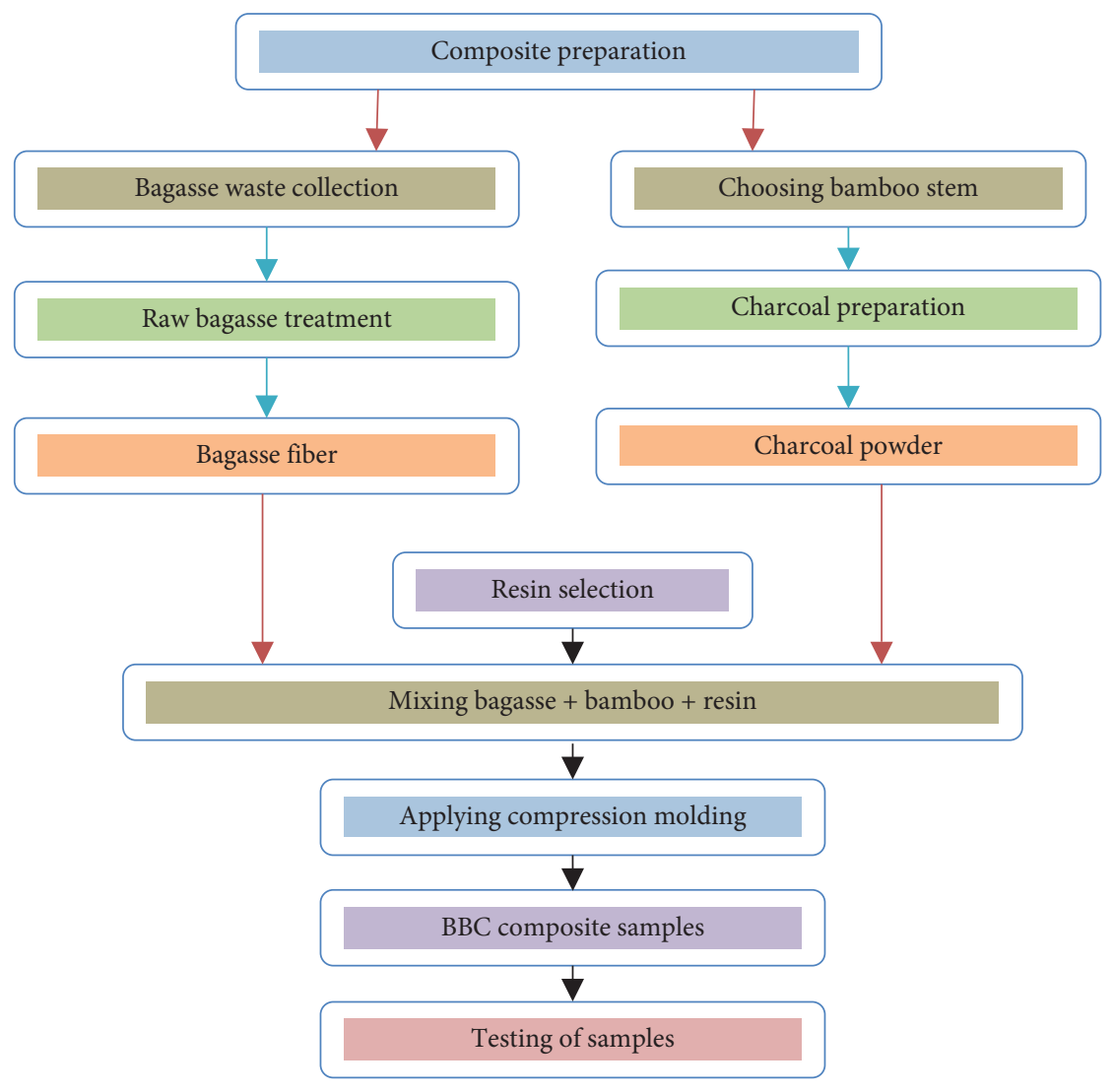

Figure 3: Composite fabrication process.

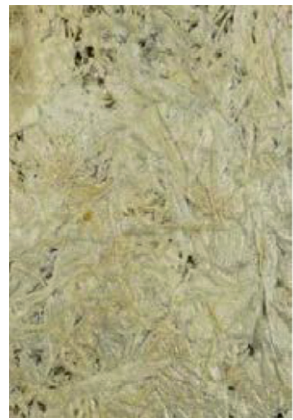

(a)

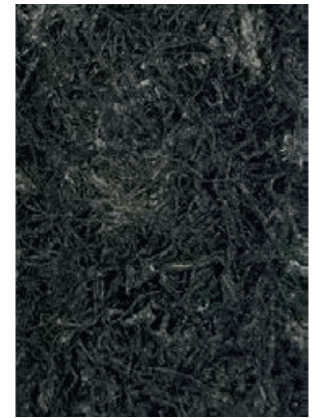

(b)

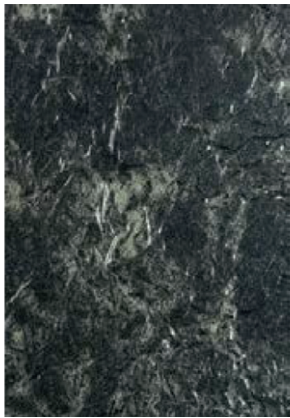

(c)

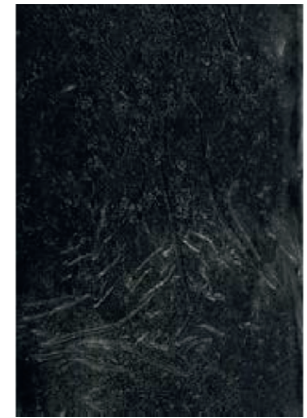

(d)

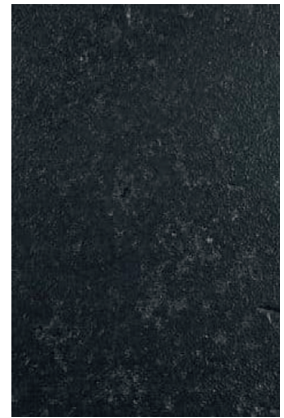

(e)

FIgure 4: Developed composite plates. (a) BBC-A; (b) BBC-B; (c) BBC-C; (d) BBC-D; (e) BBC-E. 
2.3.3. Impact Test. The impact test samples are prepared in accordance with ASTM D 256 standards. The prepared samples are placed on the Izod machine. The specimen is loaded onto the pendulum impact tester for sticking and then determining the behaviour and service life of the composite samples at high deformation speeds. The noted result which is required to break the specimen is the function of energy. It is used to measure the yield properties of fiberreinforced polymer composites. To avoid the manual error, a minimum of four tastings are taken, and the average reading is finalized.

2.4. Scanning Electron Microscope (SEM). The interfacial bonding and nature of the fibers on composites are investigated through scanning electron morphological (SEM) analysis. The SEM test was conducted on fabricated fiberreinforced polymer composite specimens measured by using ASTM D 256 standard using a JEOL SEM instrument; the morphological analysis was performed on cryogenically fractured surfaces of composite samples. After tensile testing, the fractured surfaces of the developed composites are examined using a scanning electron microscope (SEM) JEOL JSM-6480LV as shown in Figure 5.

2.5. Thermal Conductivity. The coefficient of specimens' thermal conductivity was measured using Lee's disk method principle [27]:

$$
\begin{aligned}
Q & =V I \\
& =a_{A} T_{A}+a_{s} T_{A}+T_{B}+A_{B} T_{B}+a_{c} T_{c}, \\
K & =\left(\frac{Q t_{s}}{T_{B}-T_{A}}\right)\left(\frac{T_{A}+2 T_{A}}{r}\left(\frac{t_{A}+t_{S}}{4}\right)+\frac{t_{S} T_{B}}{2 r}\right) .
\end{aligned}
$$

Thermal conductivity of samples was then calculated theoretically by using Maxwell's model as illustrated above, where comparisons between theoretical and experimental results were accomplished. The thermal conductivity was determined in accordance with ASTM D 6343.

\section{Results and Discussions}

The mechanical properties, namely, tensile strength, flexural strength, impact strength, and hardness value of fabricated fiber-reinforced polymer composites, are experimentally evaluated. The average results of each are given Table 2 .

3.1. Tensile Strength. For the composite, it is found that the mechanical properties of the sample C (E65-S20-J15) are higher than other different examples. This is because of the expansion in the weight level of jute fiber. Sample $\mathrm{C}$ has more tensile, flexural, and impact strength $(28.142 \mathrm{MPa}$, $67.58 \mathrm{MPa}$, and $0.85 \mathrm{~J} / \mathrm{m}^{2}$, respectively) than other two samples (A and B).

As can be seen clearly from Figures 6-9 for BBC-A, BBC$\mathrm{C}, \mathrm{BBC}-\mathrm{D}$, and $\mathrm{BBC}-\mathrm{E}$, respectively, that the tensile strengths of the samples are taken, distinctive weight proportions are taken, and the outcomes are noted. It is found that the BBCE sample has a most extreme tensile strength of $15.4 \mathrm{kN}$ in which the tensile properties, like critical stress and tensile modulus, reached their ultimate values followed by sample BBC-D and BBC-C with $10.9 \mathrm{kN}$ and $8.7 \mathrm{kN}$, respectively. The obtained results from the tensile test of fabricated fiberreinforced hybrid composites are presented in Figure 10. The result indicated that the $\mathrm{BBC}-\mathrm{E}$ composite specimen has better tensile strength than the other components of the specimen. But at the same time, bagasse fiber loaded with charcoal powder composite has almost the same strength ( $2 \%$ of deviation takes place). The bagasse fiber alone produces a very minimum strength $(185.50 \mathrm{MPa})$, but the considerable amount of strength increased with the proper mixing ratio of bagasse and charcoal and powder. The tensile strengths of $232.20 \mathrm{MPa}$ and $255.80 \mathrm{MPa}$ are obtained by the addition of $10 \%$ and $20 \%$ volume of bagasse fiber with charcoal. The overloading of bagasse fiber on composite produces less strength due to weak interfacial bond increased between fiber and matrix materials. It clearly shows that the addition of natural fiber with charcoal powder materials produces a better result than the uses of natural fiber alone. By the way, natural fiber composites are effectively used in tensile applications. The same results were obtained in [28].

3.2. Flexural Test. The different samples' flexural strength is shown in Figure 11. The flexural strength of composite is better due to the gradual decrease of percentage weight of bagasse fiber (100\% to $0 \%)$ and gradual increase of weight percentage of bamboo charcoal (0\% to $100 \%)$. Sample BBC$\mathrm{D}$ has more flexural strength than the other four samples, with a maximum flexural strength of $84 \mathrm{MPa}$, whereas BBC$\mathrm{C}$ and $\mathrm{BBC}-\mathrm{E}$ have $78 \mathrm{MPa}$ and $76 \mathrm{MPa}$, respectively. The bagasse fiber composite (BBC-E) has more strength as compared to other composite specimens. Meanwhile, the same strength produced on bagasse fiber added charcoal powder composites (BBC-D). The composites are capable of carrying a flexural load of $4.19 \mathrm{kN}$ whereas BBC-C composites are capable of taking a flexural load up to $4.36 \mathrm{kN}$. It is clearly shown that $100 \%$ bagasse fiber composites have very low load carrying as compared to other composites ratios. The same strength variation appeared in tension test of fabricated composites [29].

3.3. Impact Test. The impact strength of sample BBC-D is superior to the next four samples of composites with the most extreme effect strength estimation of $0.85 \mathrm{~J} / \mathrm{m}^{2}$, whereas sample BBC-B has $0.42 \mathrm{~J} / \mathrm{m}^{2}$ and sample BBC-A has $0.37 \mathrm{~J} / \mathrm{m}^{2}$. Because of fiber pullout and fiber breakage, the impact strength is low at lower stacking of fiber. The more fiber stacking of biocomposite displays higher interfaces on the break way upgraded to more impact strength [30]. The expanded fiber stacking prompts improving the impact strength. The expansion measure of bamboo charcoal content improves the tensile strength of the hybrid composite together with bagasse fiber. For analyzing the impact properties of composite specimen, the test samples have 


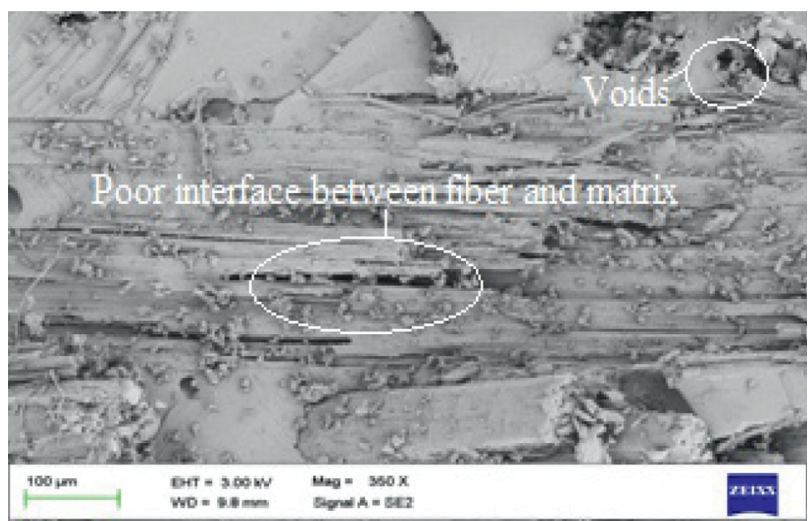

(a)

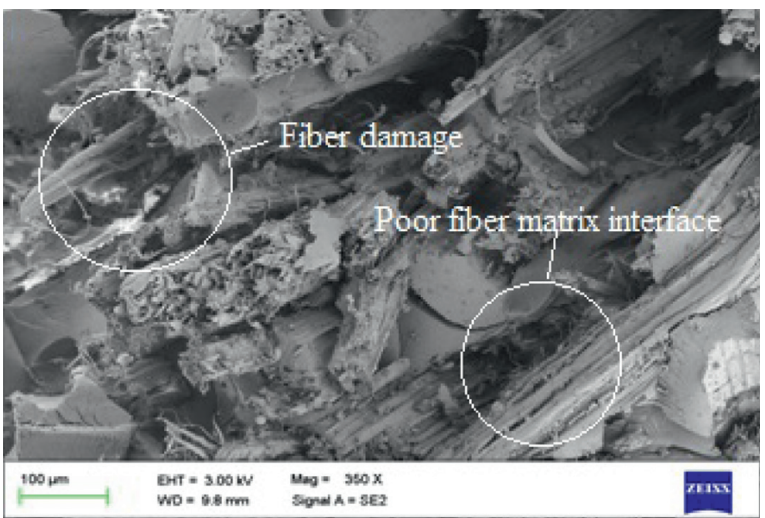

(b)

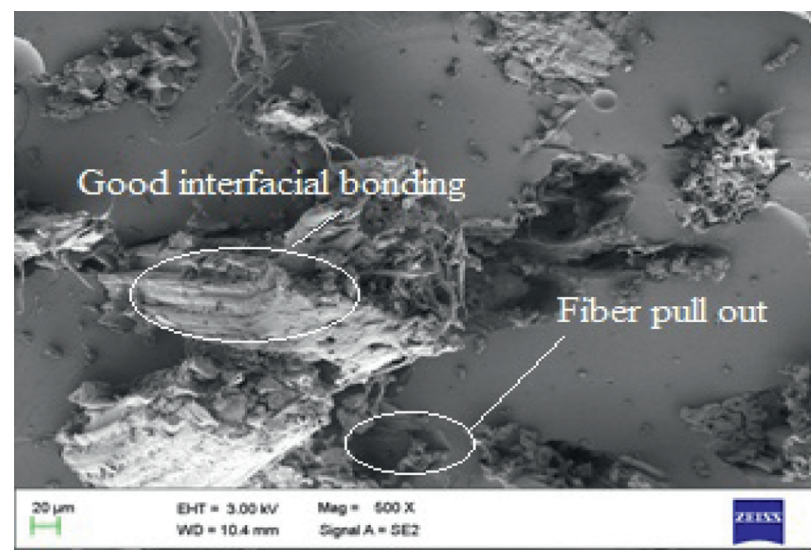

(c)

Figure 5: Tensile test SEM images of sample A (a), sample B (b), and sample C (c).

TABLE 2: Physical and mechanical properties of sample composite materials.

\begin{tabular}{lccccc}
\hline Samples & Tensile strength $(\mathrm{MPa})$ & Flexural strength $(\mathrm{MPa})$ & Impact strength $\left(\mathrm{J} / \mathrm{m}^{2}\right)$ & Porosity & Thermal conductivity $(\mathrm{W} / \mathrm{mK})$ \\
\hline BBC-A & 3.4 & 72 & 0.37 & 0.497 & 0.130 \\
BBC-B & 7.2 & 75 & 0.42 & 0.291 & 0.124 \\
BBC-C & 8.7 & 78 & 0.56 & 0.164 & 0.120 \\
BBC-D & 10.9 & 84 & 0.85 & 0.198 & 0.084 \\
BBC-E & 15.4 & 76 & 0.81 & 0.088 & 0.086 \\
\hline
\end{tabular}

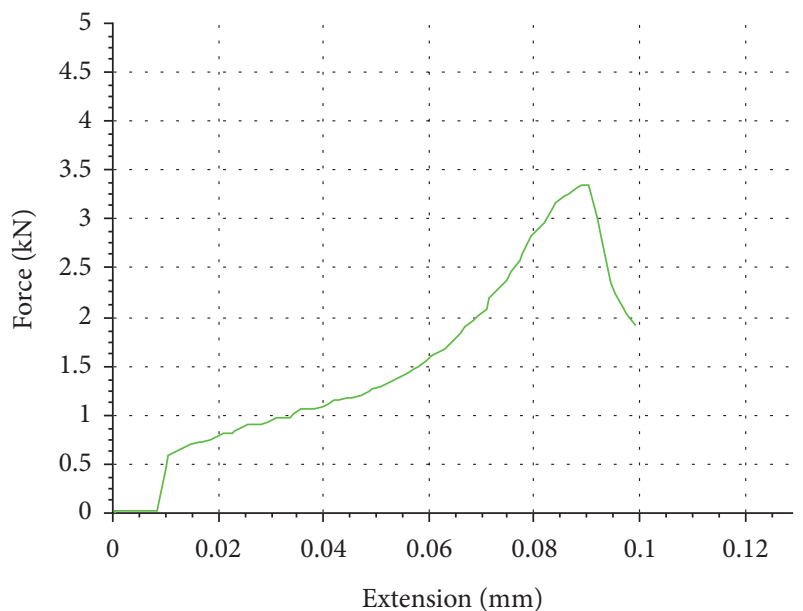

Figure 6: BBC-A.

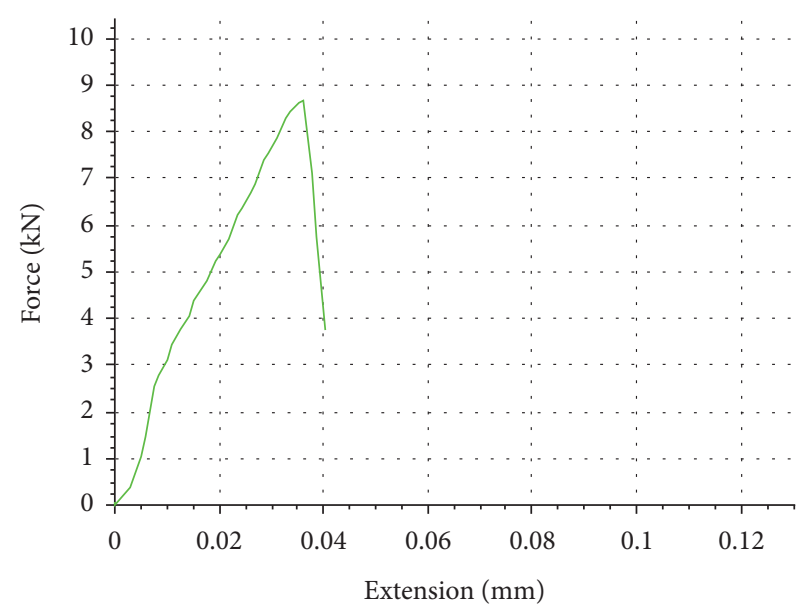

Figure 7: BBC-C. 


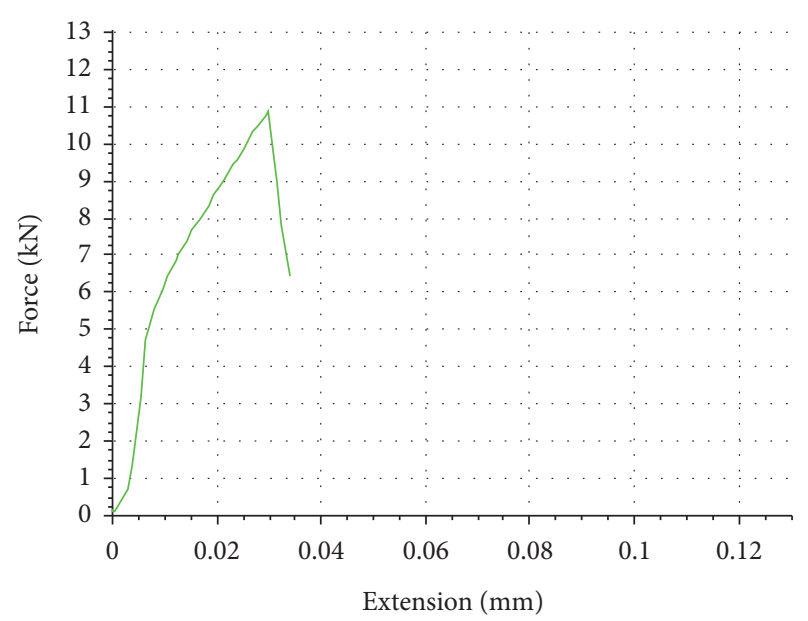

Figure 8: BBC-D.

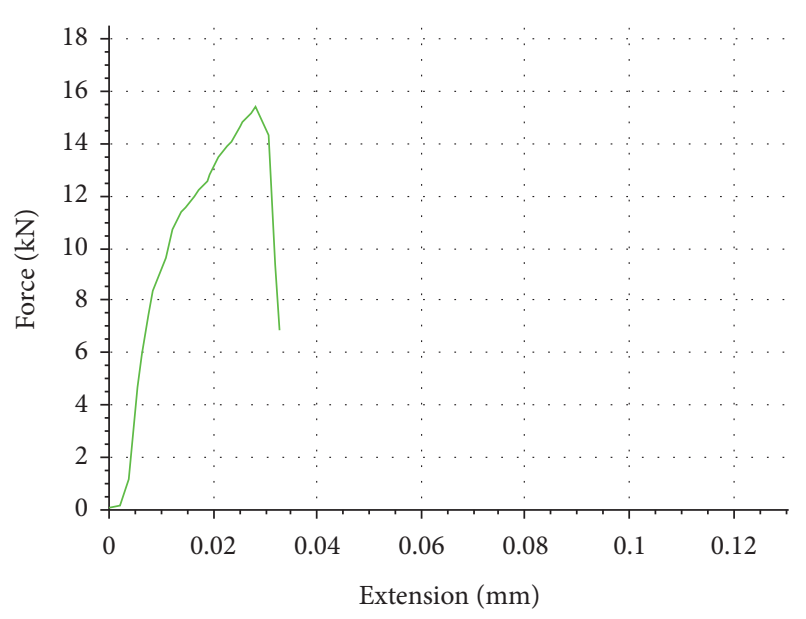

Figure 9: BBC-E.

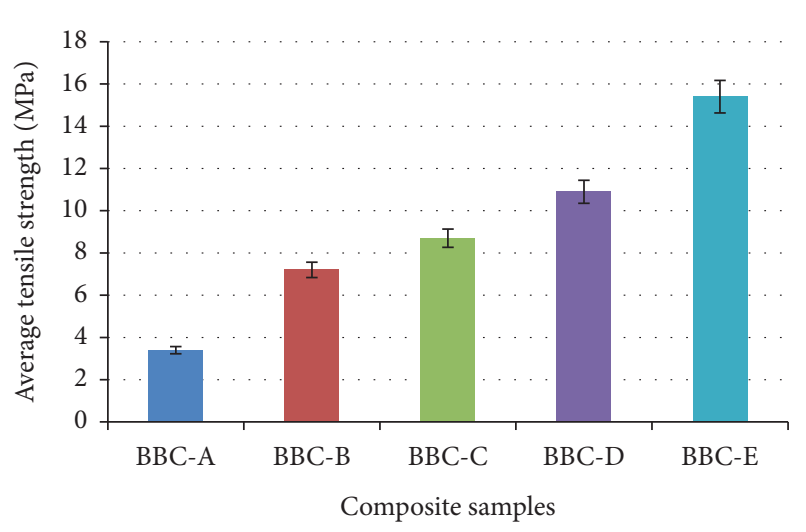

FIgURE 10: Tensile strength of composite samples.

undergone an impact test, and the average result of each composition is shown in Figure 12. The impact strength of bagasse added to charcoal powder composite produces better result than the glass fiber composites. Those impact

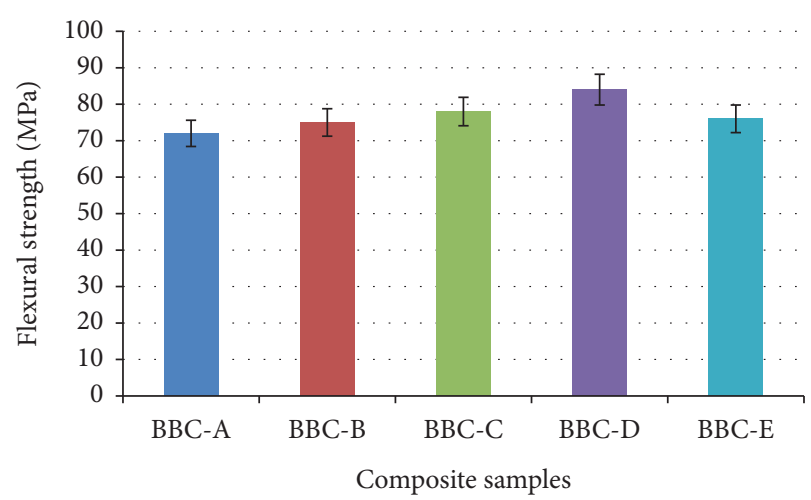

Figure 11: Flexural strength of composite samples.

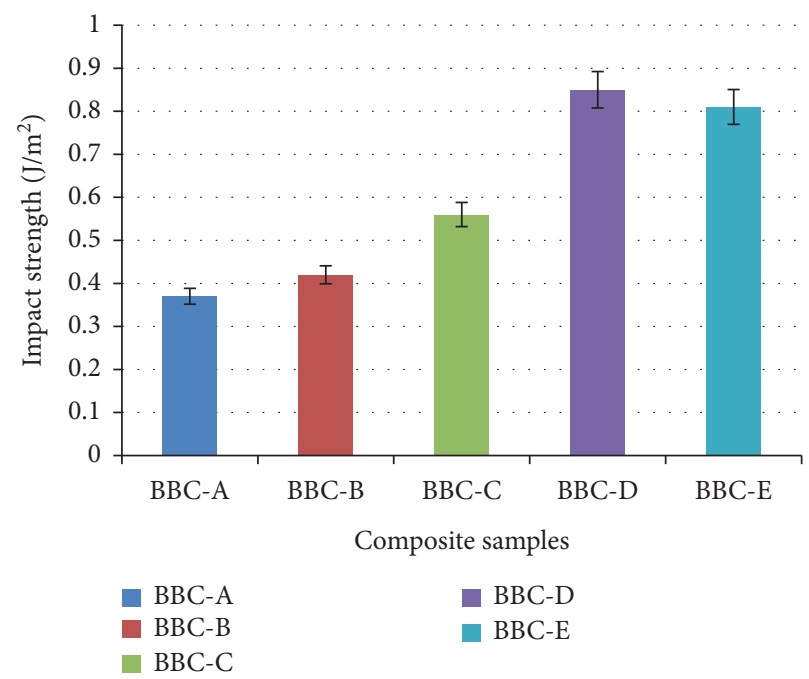

FIGURE 12: Impact strength of composite samples.

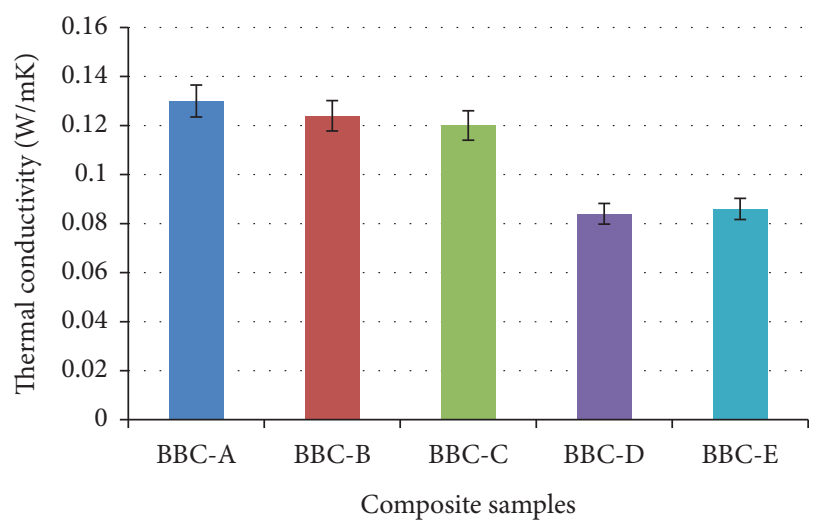

Figure 13: Thermal insulation behavior of composites.

strength results entirely differ from the other strength. During the test, the sisal fiber is not pull out easily as compared to glass fiber. So, more energy is required to break the fabricate specimens $\left(2.52 \mathrm{~J} / \mathrm{mm}^{2}\right)$. The long fiber usages on developed composites produce high impact strength. At 
the same time, short fiber is not producing that much strength. Hence, the bagasse content added to charcoal powder (BBC-E) composites is more suitable for impact strength applications. The same results were obtained by [31].

3.4. Scanning Electron Microscope (SEM). Based on ASTM D 256 [32], the SEM pictures of photography of different tensile test samples are shown in Figure 5. For the hybrid composite samples, the fiber pullout wonder was investigated. Because of fiber pullout, not many voids and more fiber breakage are noticed. Figure 5(a) shows the SEM pictures of sample A. This sample has lower strength attributes than different samples. The fiber pullout and fiber scratch of the sample have diminished its solidarity and uniqueness. Insufficient fiber-matrix interfacial holding speaking to the low tensile strength is found in Figure 5(b). Figure 5(c) shows the SEM picture of sample C. Because of fiber pullout, not many voids and more fiber breakage are seen in sample C. It is plainly shown the improved interlinkage holding among matrix and fiber. This plainly demonstrates that the holding among fiber and lattice improves the definitive tensile strength [33]. Due to the poor adhesion of fibers, they were not properly bonded with resin; also the unmixture fibers were noticed, and hence, it leads to propagation while testing. For achieving a reduction in fiber pullout with maximum withstanding capacity, there should be a better bond in between the bagasse fibers, bamboo charcoal, and resin material in the composite morphological structure.

3.5. Thermal Insulation. The thermal insulation properties of the five samples were measured in terms of the thermal conductivity testing procedure [34]. The better the thermal conductivity, the better the insulation property and thermal conductivities of various samples are shown in Figure 13. A lower value of the thermal conductivity implies that there is a higher resistance to conduction of the heat through the composite material. With the increase in temperature, the thermal conductivity increases for all the samples. The BBCD composite sample with bagasse/bamboo ratio of 30/70 provides the best thermal insulation property, which is suitable for automotive interiors for a heat-absorbing specific application as studied in $[35,36]$. Thermal conductivity values for $\mathrm{BBC}-\mathrm{A}$ and $\mathrm{BBC}-\mathrm{C}$ are 0.130 and 0.124 , respectively. BBC-A has a better thermal insulation value than BBC-C. Fiber composite insulation combines the advantages of strength and density with excellent insulating properties are in an evolving group of high potential engineering materials in addition to providing high resistance to chemicals, heat, and fire.

\section{Conclusion}

The properties of natural fiber-reinforced composites filled with charcoal powders are significantly influenced by the fiber parameters. The void content of the composites increases with the increase in both fiber content and fiber length. The strength properties of composites increase with an increase in the fiber content up to 15 wt. \% and then decrease. Therefore, the optimum fiber content is found to be $15 \mathrm{wt}$. \% for better mechanical properties. The mechanical and thermal insulation coefficient of the distinctive weight proportions of the composite samples was tried, and the accompanying perceptions are noted. The developed composites were tested for thermal insulation properties measured by ASTM D 6343. It is observed that BBC composites with $30 \%$ bagasse fiber and $70 \%$ bamboo charcoal achieved the higher absorption coincident in lower frequency levels with the best flexural and impact strength results, which confirms that the tensile stresses of the composite materials have a great impact on the structural performance. There were no significant changes in the thermal insulation properties of the composites when the sample composites are evaluated under high humidity conditions. Due to poor interfacial bonding, the SEM images of fiber are detached from the resin with no pullout bagasse fibers from the body of composites. Sample BBC-D has shown the better properties of thermal insulation and these developed composite products can be used for major technical applications and can be suggested for automotive interiors. In the future, the scope of this research work can conclude that the thermal and mechanical properties of natural fiber composite materials were greatly improved by lamination with the opportunity to access the new range of automotive applications.

\section{Data Availability}

The experimental data used in supporting these investigations are included within the research study.

\section{Conflicts of Interest}

The authors declare that they have no conflicts of interest regarding the publication of this study.

\section{Acknowledgments}

The authors would like to thank the staff of Textile Technology Department at Ethiopian Technical University for their encouragement and unlimited guidance.

\section{References}

[1] L. L. Naik, K. Gopalakrishna, and B. Yogesha, "Review on mechanical properties of sisal and banana reinforced composites," Cellulose, vol. 66, p. 78, 2015.

[2] M. Ramesh, K. Palanikumar, and K. H. Reddy, "Plant fibre based bio-composites: sustainable and renewable green materials," Renewable and Sustainable Energy Reviews, vol. 79, pp. 558-584, 2017.

[3] V. Vidyashri, H. Lewis, P. Narayanasamy, G. T. Mahesha, and K. S. Bhat, "Preparation of chemically treated sugarcane bagasse fiber reinforced epoxy composites and their characterization," Cogent Engineering, vol. 6, no. 1, Article ID 1708644, 2019.

[4] M. Asrofi, S. M. Sapuan, R. A. Ilyas, and M. Ramesh, "Characteristic of composite bioplastics from tapioca starch 
and sugarcane bagasse fiber: effect of time duration of ultrasonication (Bath-Type)," Materials Today: Proceedings, vol. 46, 2020.

[5] C. Van Dillewijn, Botany of Sugarcane, Chronica Botanica, Waltham, MA, USA, 1952.

[6] Instituto de investigaciones de la caña de azúcar, La industria de los derivados de la caña de azúcar, Editorial científicotécnica La Habana, Havana, Cuba, 1980.

[7] A. Berghezan, "Non-ferrous Materials.design and strength analysis of a hybrid composite of carbon, glass and basalt fiber," Nucleus, vol. 8, pp. 5-11, 1966.

[8] V. Suchtelen, "Product properties: a new application of composite materials," Philips Research Reports, vol. 27, pp. 28-37, 1972.

[9] G. T. Mahesha, K. SubrahmanyaBhat, and N. H. Padmaraja, "Biodegradable natural fiber reinforced polymer matrix composites: technical updates," AIP Conference Proceedings, vol. 2166, Article ID 020001, 2019.

[10] G. Gunasekaran, C. Prakash, and S. Periyasamy, "Preparation, characterisation of bamboo charcoal particles and the effect of their application on thermo-physiological comfort properties of woven fabrics," Journal of the Textile Institute, vol. 111, no. 3, pp. 318-325, 2020.

[11] Z. Qisheng, J. Shenxue, and T. Yongyu, Industrial Utilization on Bamboo, International network for bamboo and rattan, Beijing, China, 2002.

[12] S. Bonilla, R. L. Guarnetti, C. M. V. B. Almeida, and B. F. Giannetti, "Sustainability assessment of a giant bamboo plantation in Brazil: exploring the influence of labour, time and space," Journal of Cleaner Production, vol. 18, no. 1, pp. 83-91, 2017.

[13] M. Ramesh, L. RajeshKumar, and V. Bhuvaneshwari, "Bamboo fiber reinforced composites," in Bamboo Fiber Composites. Composites Science and Technology, M. Jawaid, S. MavinkereRangappa, and S. Siengchin, Eds., Springer, Berlin, Germany, 2021.

[14] P. Noorunnisa Khanam, H. P. S. Abdul Khalil, G. Ramachandra Reddy, and S. V. Venkata Naidu, "Tensile, flexural and chemical resistance properties of sisal fibre reinforced polymer composites: effect of fibre surface treatment," Journal of Polymers and the Environment, vol. 19, no. 1, pp. 115-119, 2011.

[15] G. Constable, D. Llewellyn, S. A. Walford, and J. D. Clement, "Cotton breeding for fiber quality improvement," Industrial Crops: Breeding for Bioenergy and Bioproducts, Springer, Berlin, Germany, 2015.

[16] S. K. Saw, K. Akhtar, N. Yadav, and A. K. Singh, "Hybrid composites made from jute/coir fibers: water absorption, thickness swelling, density, morphology, and mechanical properties," Journal of Natural Fibers, vol. 11, no. 1, pp. 39-53, 2014.

[17] M. Jawaid and H. P. S. Abdul Khalil, "Cellulosic/synthetic fibre reinforced polymer hybrid composites: a review," Carbohydrate Polymers, vol. 86, no. 1, pp. 1-18, 2011.

[18] H. P. S. Abdul Khalil, I. U. H. Bhat, M. Jawaid, A. Zaidon, and D. Hermawan, Y. S. Hadi, "Bamboo fibre reinforced biocomposites: a review," Materials \& Design, vol. 42, pp. 353$368,2012$.

[19] J. E. G. Van Dam, H. W. Elbersen, and C. M. Daza Montaño, "Bamboo production for industrial utilization," Perennial Grasses for Bioenergy and Bioproducts, Elsevier, Amsterdam, Netherlands, 2018.

[20] M. Nasir, R. Hashim, O. Sulaiman et al., "Natural fiber improvement by laccase; optimization, characterization and application in medium density fiberboard," Journal of Natural Fibers, vol. 14, no. 3, pp. 379-389, 2017.

[21] J. Anggono, S. Sugondo, and N. R. Habibi, "Alkali Treatment o Sugarcane Bagasse To Improve Properties o Green Composites o Sugarcane Bagasse Fibers-Polypropylene," Doctoral dissertation, John Wiley, Hoboken, NJ, USA, 2015.

[22] S. Jiang, "Training manual of bamboo charcoal for producers and consumers," Bamboo Engineering Research Center, Nanjing Forestry University, Nanjing, China, 2004.

[23] G. T. Mahesha, S. B. Satish, M. V. Kini, and B. K. Subrahmanya, "Mechanical characterization and water ageing behavior studies of grewia serrulata bast fiber reinforced thermoset composites," Journal of Natural Fibers, vol. 14, no. 6, pp. 788-800, 2017.

[24] N. H. Mostafa, Z. Ismarrubie, S. Sapuan, and M. Sultan, "Fibre prestressed polymer-matrix composites: a review," Journal of Composite Materials, vol. 51, no. 1, pp. 39-66, 2017.

[25] S. Ragunath, C. Velmurugan, T. kannan, and S. Thirungnanam, "Evaluation of tensile, flexural and impact properties on sisal/glass fiber reinforced polymer hybrid composites," Indian Journal of Engineering and Materials Sciences, vol. 25, pp. 425-431, 2018.

[26] J. Moylan: Considerations for ASTM D3039 Composite Tensile Testing," Element, 02/01/17, https://www.element. com/.

[27] F. M. Saleem, "Thermal and mechanical investigation of fiberreinforcedepoxy," Ph. D. thesis, Mechanical Engineering Department, University of Technology, Baghdad, Iraq, 2006.

[28] N. H. Mostafa, Z. N. Ismarrubie, S. M. Sapuan, and M. T. H. Sultan, "Effect of equi-biaxially fabric prestressing on the tensile performance of woven E-glass/polyester reinforced composites," Journal of Reinforced Plastics and Composites, vol. 35, no. 14, pp. 1093-1103, 2016.

[29] D. S. V. Janaina, P. D. L. Felipe, and M. D. M. Ygor, "Comparative mechanical analysis of epoxy composite reinforced with malva/jute hybrid fabric by Izod and charpy impact test," in Characterization of Minerals, Metals, and Materials 2018, B. Li, Ed., Springer, Berlin, Germany, 2018.

[30] M. Boopalan, M. Niranjana, and M. J. Umapathy, "Study on the mechanical properties and thermal properties of jute and banana fiber reinforced epoxy hybrid composites," Composites Part B: Engineering, vol. 51, 2013.

[31] E. Laranjeira, L. H. Carvalho, S. M. De L. Silva, and J. R. M. D'Almeida, "Influence of fiber orientation on the mechanical properties of polyester/jute composites," Journal of Reinforced Plastics and Composites, vol. 25, no. 12, pp. 1269-1278, 2006.

[32] M. Idicula, N. R. Neelakantan, Z. Oommen, K. Joseph, and S. Thomas, "A study of the mechanical properties of randomly oriented short banana and sisal hybrid fiber reinforced polyester composites," Journal of Applied Polymer Science, vol. 96, no. 5, pp. 1699-1709, 2005.

[33] O. John and H. Uguru, "Evaluation of the mechanical and electrical properties of carbon black/carbonized snail shell powder hybridized conductive epoxy composite," International Journal of Innovative Scientific \& Engineering, vol. 9, 2021.

[34] K.-Y. Lee, K. Ho, K. Schlufter, and A. Bismarck, "Hierarchical composites reinforced with robust short sisal fibre preforms utilising bacterial cellulose as binder," Composites Science and Technology, vol. 72, no. 13, pp. 1479-1486, 2012.

[35] N. H. Mostafa, Z. N. Ismarrubie, S. M. Sapuan, and M. T. H. Sultan, "Fibre prestressed composites: theoretical and numerical modelling of unidirectional and plain-weave 
fibre reinforcement forms," Composite Structures, vol. 159, pp. 410-423, 2017.

[36] F. Mustapha, K. D. MohdAris, N. A. Wardi, M. T. H. Sultan, and A. Shahrjerdi, "Structural health monitoring (SHM) for composite structure undergoing tensile and thermal testing," Journal of Vibroengineering, vol. 14, no. 3, pp. 1342-1353, 2012. 